\title{
PHOTOELECTROCHEMICAL SOLAR ENERGY CONVERSION BASED ON BLEND OF POLY(3-HEXYLTHIOPHENE) (P3HT) AND 1-(3-METHOXYCARBONYL) PROPYL-1-PHENYL [6,6]C 61 (PCBM)
}

\author{
Sisay Tadesse ${ }^{*}$ and Teketel Yohannes \\ Department of Chemistry, College of Natural Sciences, Addis Ababa University, P.O. Box \\ 1176, Addis Ababa, Ethiopia
}

(Received October 26, 2011; revised January 2, 2012)

\begin{abstract}
A solid-state photoelectrochemical solar energy conversion device based on blend of poly(3hexylthiophene) (P3HT) and 1-(3-methoxycarbonyl)propyl-1-phenyl[6,6]C 61 (PCBM), and an amorphous poly(ethylene oxide) complexed with $\mathrm{I}_{3}{ }^{-} \mathrm{I}^{-}$redox couple has been constructed and characterized. The photoelectrochemical performance parameters of the device were compared with pure P3HT and P3HT: $\mathrm{C}_{60}$ blend solid-state photoelectrochemical cell. The current density-voltage characteristics in the dark and under white light illumination and photocurrent spectra for front and backside illuminations have been studied. An open-circuit voltage of $140 \mathrm{mV}$ and a short-circuit current density of $28.4 \mu \mathrm{A} / \mathrm{cm}^{2}$ at light intensity of $100 \mathrm{~mW} / \mathrm{cm}^{2}$; IPCE\% of $1.52 \%$ for front side illumination (ITOIPEDOT) and IPCE\% of $0.17 \%$ for backside illumination (ITOIP3HT:PCBM) at a wavelength of $510 \mathrm{~nm}$ were obtained. The dependence of the short-circuit current density and an open-circuit voltage on the light intensity and time have also been studied.
\end{abstract}

KEY WORDS: Poly(3-hexylthiophene), PCBM, Amorphous poly(ethylene oxide), $\mathrm{I}_{3}{ }^{-} / \Gamma^{\top}$ redox couple, Solidstate photoelectrochemical cell

\section{INTRODUCTION}

A type of the photocurrent-generated device that has a semiconductor in contact with an electrolyte is referred as photoelectrochemical cell (PEC). A photoelectrochemical cell consists of a photoactive semiconductor working electrode (either n- or p-type) and counter electrode made of metal (e.g. Pt). Both electrodes are immersed in the electrolyte containing suitable redox couples. In a semiconductor-electrolyte junction, the potential drop occurs on the semiconductor side as well as the solution side. The charge on the semiconductor side is distributed deep in the interior of the semiconductor, creating a space charge region. If the junction of the semiconductor-electrolyte is illuminated with a light having energy greater than the bandgap of the semiconductor, photogenerated electrons/holes are separated in the space charge region. The photogenerated minority carriers arrive at the interface of the semiconductorelectrolyte.

Photogenerated majority carriers accumulate at the backside of the semiconductor. With the help of a connecting wire, photogenerated majority carriers are transported via a load to the counter electrode where these carriers electrochemically react with the redox electrolyte. A pioneering photoelectrochemical experiment was realized by obtaining photocurrent between two platinum electrodes immersed in the electrolyte containing metal halide salts [1]. It was later found that the photosensitivity can be extended to longer wavelengths by adding a dye to silver halide emulsions [2]. The interest in photoelectrochemistry of semiconductors led to the discovery of wet-type photoelectrochemical solar cells [3-5]. These studies showed electron transfer to be the prevalent mechanism for photoelectrochemical sensitization processes. Grätzel has then extended the concept to the dye sensitized solar cells (DSSC).

*Corresponding author. E-mail: sisaytad@gmail.com 
When shining the light, oxidation reaction will occur on the surface of n-type semiconductors, whilst reduction reaction will occur on the surface of p-type semiconductors. In the PEC, which is based on a narrow bandgap semiconductor and a redox couple, optical energy is converted into electrical energy without change of the free energy of the redox electrolyte $(\Delta \mathrm{G}$ $=0$ ). The electrochemical reaction occurring at the counter electrode $(\mathrm{CE})$ is opposite to the photoassisted reaction occurring at the semiconductor working electrode. Thus, they are also called regenerative PECs [6-10]. If the photogenerated energy is converted to chemical energy, the free energy of the electrolyte will have a change $(\Delta G \neq 0)$. Depending on the relative location of the potentials of the two redox couples, the photosynthetic cells containing two redox couples, can be further classified as photocatalytic cell $(\Delta \mathrm{G}<0)$ where light merely serves to accelerate the reaction rate and phtoelectrolytic cell $(\Delta \mathrm{G}>0)$ where the cell reaction is driven by light in the opposite-thermodynamic direction. Comparing with regenerative PECs, anodic and cathodic compartments need to be separated to prevent the mixing of the two redox couples in these types of cells. Titanium dioxide $\left(\mathrm{TiO}_{2}\right)$ has been favored semiconductor for such studies [11]. As early as 1971, photoelectrolysis of water was reported in an electrochemical cell with a $\mathrm{TiO}_{2}$ photoanode and a Pt cathode without an external source [12].

One of the most important aspects in using solar energy is its conversion from solar radiation into electric energy. Photoelectrochemical cells have the following advantages comparing with the solid photovoltaics. (1) It is not sensitive to the defects in semiconductors. (2) The solid/liquid junction is easy to form and the production price will be much reduced. (3) It is possible to realize the direct energy transfer from photons to chemical energy.

The most striking difference between a PEC and the conventional Si based photovoltaics is that the former contains two interfaces at which charge transport has to switch from electronic to ionic and vice versa, as in batteries. In PECs without dyes, both the semiconductor electrode and the counter electrode are immersed in the redox electrolyte. The incident light excites the semiconductor electrode and the photogenerated electrons and holes are seperated in the space charge region. Specific reactions occur only at the semiconductor and the metal. In these kinds of cell, charge balance due to oxidation and reduction processes is maintained.

Increasingly, there is an awareness of the possible advantages of nanocrystalline and conducting polymer devices, which are relatively cheap to fabricate (the expensive and energyintensive high-temperature and high-vacuum processes needed for the traditional devices can be avoided), can be used on flexible substrates, and can be shaped or tinted to suit domestic devices or architectural or decorative applications. It is now even possible to depart completely from the classical solid-state junction device, by replacing the phase in contact with the semiconductor by an electrolyte (liquid, gel or organic solid), thereby forming a photoelectrochemical device.

In our previous studies we reported the use of substituted polythiophenes as photoactive electrodes in solid-state PECs [13-17]. We also made the first report on solid-state photoelectrochemical energy conversion using conducting polymer poly(3-hexylthiophene) P3HT, and fullerene mixtures [18]. A better performance of the PEC will be obtained if $\mathrm{C}_{60}$ is replaced by PCBM. Padinger et al. found that the quality and the homogeneity of the polymerfullerene mixture strongly influence the efficiency of the solar cell. The functionalized side groups on PCBM give a better solubility in organic solvents compared to $\mathrm{C}_{60}$ which makes PCBM to form homogeneous films [19].

To our knowledge, there are no reports on solid-state photoelectrochemical energy conversion using conducting polymer and PCBM mixtures. In this work we report experimental results on the behaviour of a solid-state PEC containing a mixture of P3HT and PCBM coated on indium-doped tin oxide (ITO) used as a photoactive electrode; amorphous polyethylene oxide complexed with the $\mathrm{I}_{3}{ }^{-} / \mathrm{I}^{-}$redox couple used as an electrolyte; and a thin transparent layer 
of poly(3,4-ethylenedioxythiophene), PEDOT, electrochemically coated on ITO as a counter electrode.

Figure 1 shows the device structure of the solid-state PEC and the chemical structures of P3HT, PEDOT and PCBM used in this study. P3HT combines commercial availability with sufficient solubility, a low band gap relative to the most conjugated polymers and a high degree of intermolecular order leading to high-charge carrier mobility [20]. The polymer electrolyte, amorphous poly(ethylene oxide) from the poly(oxymethylene-oligo(oxyethylene) family, with a repeating unit of $\mathrm{CH}_{2} \mathrm{O}\left(\mathrm{CH}_{2} \mathrm{CH}_{2} \mathrm{O}\right)_{9}$ (POMOE), has a melting point below room temperature and a glass transition temperature of $209 \mathrm{~K}$ [21-25]. At room temperature it will not crystallize or form crystalline polymer-salt complexes with moderate salt concentrations. Electrochemically oxidized PEDOT was required on ITO because it improved charge transfer between ITO and the $\mathrm{I}_{3}{ }^{-} / \mathrm{I}$ redox couple through its catalytic behaviour [15]. It is known that bare ITO is irreversible for the $\mathrm{I}_{3}{ }^{-} / \mathrm{I}$ redox reaction [26].

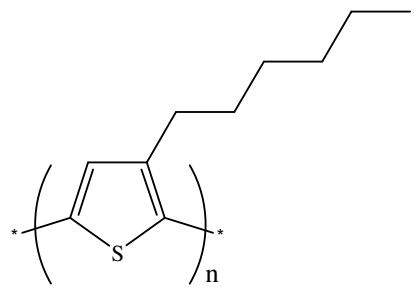

(a)

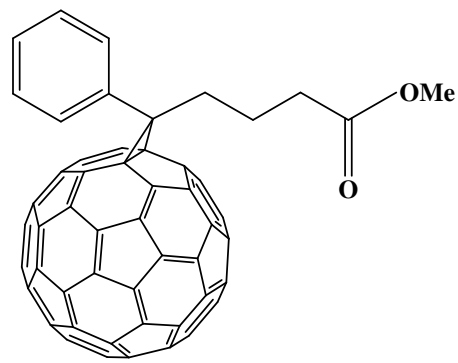

(b)

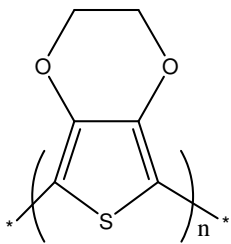

(c)

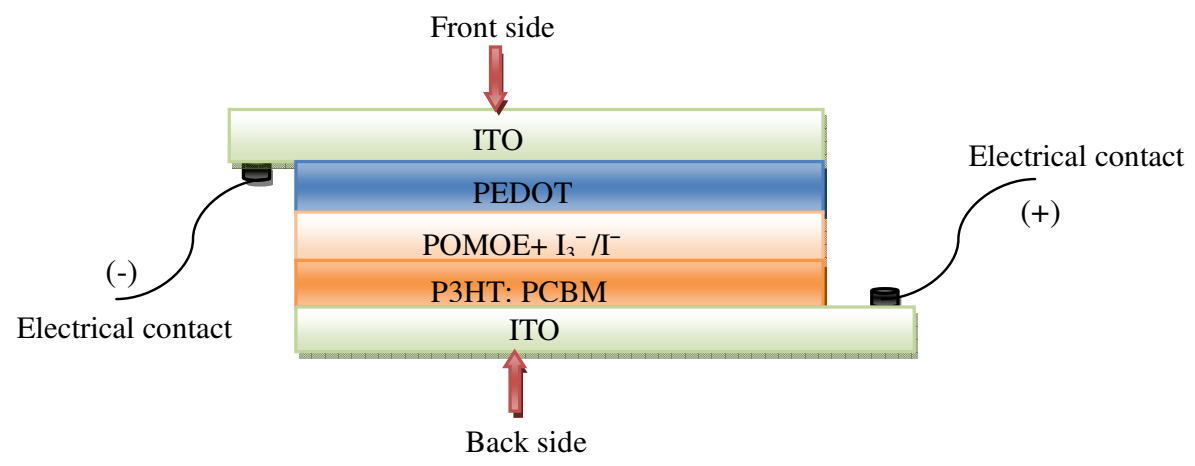

(d)

Figure 1. The Chemical structure of (a) Poly(3-hexylthiophene), P3HT, (b) 1-(3methoxycarbonyl) propyl-1-phenyl $[6,6] \mathrm{C}_{61}, \quad \mathrm{PCBM}$, and (c) Poly(3,4ethylenedioxythiophene), PEDOT and (d) the basic structure of the solid-state PEC. 


\section{EXPERIMENTAL}

In this study a blend of P3HT (Aldrich) and PCBM (Merck) was used as a photoactive electrode. Both $\mathrm{P} 3 \mathrm{HT}$ and PCBM were used without any pre-treatment. ITO-coated glass having transmittance above $80 \%$ in the visible region of the solar spectrum was employed as a substrate for the photoactive materials and counter electrodes. It was cleaned successively with acetone (Aldrich), 2-propanol (Riedel-de-Haen) and ethanol (BDH) and dried with an air gun. A solution of the photoactive electrode was prepared by dissolving a mixture of $2.5 \mathrm{mg}$ P3HT and $2.5 \mathrm{mg}$ PCBM in $1 \mathrm{~mL}$ of 1,2-dichlorobenzene (Riedel-de-Haen). The photoactive film was formed by drop casting a solution of P3HT and PCBM on a pre-cleaned ITO-coated glass.

The polymer film for the counter electrode was formed by electrochemical polymerization of 3,4-ethylenedioxythiophene (EDOT) (Bayer), in a three electrode one-compartment electrochemical cell. The electrochemical cell consisted of a pre-cleaned ITO-coated glass working electrode, platinum foil counter electrode and quasi- $\mathrm{Ag} / \mathrm{AgCl}$ reference electrode dipped in $\mathrm{LiClO}_{4}$ (Aldrich) acetonitrile (Sigma-Aldrich) solution. The solution used for the polymerization contained $0.1 \mathrm{M}$ EDOT and $0.1 \mathrm{M} \mathrm{LiClO}_{4}$ in acetonitrile. The monomer was used as received. The polymerization was carried out potentiostatically at $+1.8 \mathrm{~V}$. At this potential, the electrode surface becomes covered with blue-doped PEDOT film. The cell was then rinsed with acetonitrile and dried in air.

The polymer electrolyte was prepared by dissolving $309 \mathrm{mg}$ of POMOE in $25 \mathrm{~mL}$ of methanol (Fluka). The redox couple $\mathrm{I}_{3}{ }^{-} / \mathrm{I}^{-}$was prepared by dissolving $48.13 \mathrm{mg} \mathrm{KI}$ (BDH) and $7.36 \mathrm{mg} \mathrm{I}$ (Aldrich) separately in $25 \mathrm{~mL}$ of methanol (Fluka). Finally, $2 \mathrm{~mL}$ of each of the above three solutions were mixed to produce the polymer electrolyte complexed with a redox couple. The mole ratio of oxygen to potassium as calculated by taking into account both the oxymethylene and oxyethylene oxygen atoms was 25 and the mole ratio of $\mathrm{KI}$ to $\mathrm{I}_{2}$ was 10 , i.e. the concentration of $\mathrm{I}_{2}$ is one-tenth the concentration of KI. The ionic conductivity of POMOE is known to be high at room temperature when the oxygen to cation (potassium) mole ratio is 25 [27].

Finally, the polymer electrolyte complexed with $\mathrm{I}_{3}{ }^{-} / \mathrm{I}^{-}$was deposited in the form of thin film by solvent casting on top of P3HT:PCBM coated ITO-glass and allowed to dry in a laboratory atmosphere. The PEC was completed by pressing against PEDOT-coated ITO-glass counter electrode. The PEC was then mounted in a sample holder inside a metal box with $1 \mathrm{~cm}^{2}$ opening to allow light from the source. All experiments were carried out at room temperature.

The photoelectrochemical measurements of the cell were performed using a computercontrolled CHI630A Electrochemical Analyzer. A 250-W tungsten-halogen lamp regulated by an Oriel power supply (Model 68830) was used to illuminate the PEC. A grating monochromator (Model 77250) placed into the light path was used to select a wavelength between 300 and $800 \mathrm{~nm}$. The measured photocurrent spectra were corrected for the spectral response of the lamp and the monochromator by normalization to the response of a calibrated silicon photodiode (Hamamatsu, Model S1336-8BK) whose sensitivity spectrum was known. No correction was made for the reflection from the surface of the sample. The white light intensity was measured in the position of the sample cell with Gigahertz-Optik X $1_{1}$ Optometer. A series of neutral density filters were used to vary the light intensity incident on the sample. The optical absorption spectrum of the film was measured using Spectroscopic GENESYS 2PC UV-Vis spectrometer. 


\section{RESULTS AND DISCUSSION}

\section{Current density-voltage characteristics}

The current density from the PEC is measured as a function of the applied voltage, both in the dark, and under illumination. This data allows the $\mathrm{J}_{\mathrm{SC}}$, the $\mathrm{V}_{\mathrm{OC}}$ and the rectifying properties of the devices to be determined, and enables to calculate the fill factor. Figure 2 show the current density-voltage curves of the PECs based on a blend of P3HT:PCBM, in the dark and under white light illumination at $100 \mathrm{~mW} / \mathrm{cm}^{2}$, respectively. The devices were illuminated from their front sides (ITOIPEDOT).

In the dark, the current was negligible and remained relatively constant in the negative potential range while a larger anodic current was observed in the larger positive potential range. The current-voltage characteristic of the cell in the dark is described mathematically by Equation (1) [28]:

$$
I=I_{0}\left[\exp \left(\frac{q V}{n k T}\right)-1\right]
$$

where $I_{0}$ is the saturation current, $q$ the electron charge, $k$ the Boltzmann constant, $T$ the absolute temperature, $V$ the applied voltage, and $n$ the ideality factor. The positive applied potential acts to diminish the effects of the internal barrier field that is set at the polymer/electrolyte junction. As a result, charge carriers acquire enough energy to cross the barrier, resulting with large anodic currents. On the other hand, applying a negative potential enhances the barrier potential and only a small current flows. The current response of the devices to the applied potentials in the dark indicates that the devices exhibit the desirable photoelectrochemical properties. Under illumination, cathodic photocurrents were observed that extend from a negative potential range up to a positive potential range, which is expressed as the open-circuit voltage (The voltage where the current is zero). This indicates that the direction of the photoinduced charge separation is the same as that of the charge separation by the applied potential. The currentvoltage characteristic under illumination can be described by Equation (2) [28]:

$$
I=I_{p h}-I_{0}\left[\exp \left(\frac{q V}{n k T}\right)-1\right]
$$

where $I_{p h}$ is the photogenerated minority carrier current (which is opposite in sign to the dark current) and is equal to the product of the absorbed photon flux and the charge on an electron. The $\mathrm{V}_{\mathrm{OC}}$ of Bulk heterojunction (BHJ) based solar cells is strongly correlated to inherent material properties. It was demonstrated that the open circuit voltage of polymer/fullerene BHJ based solar cells is correlated to the reduction potential of the fullerene molecule [29]. A reduction potential defines the LUMO level of the molecule. Moreover, the $\mathrm{V}_{\mathrm{OC}}$ of polymer/fullerene based solar cells is affected by the morphology of the active layer [30]. From Table 1, it can be seen that the P3HT:PCBM based device exhibits many fold improvement in the short-circuit current density, higher $\mathrm{V}_{\mathrm{OC}}$ when compared with the P3HT: $\mathrm{C}_{60}$ [18] based device. Higher $\mathrm{V}_{\mathrm{OC}}$ and the several fold enhancement in the short circuit current density of P3HT:PCBM based device most likely originates from the enhanced charge carrier separation and improved charge carrier mobility [31] due to better solubility of mixture of P3HT with $\mathrm{PCBM}$ in an organic solvent which also results in better morphology and homogeneity compared with mixture of $\mathrm{P} 3 \mathrm{HT}$ with $\mathrm{C}_{60}$ in the same organic solvent [19]. 
Table 1. Typical photoelectrochemical parameters calculated from J-V characteristics for P3HT:PCBM PEC compared with P3HT:C 60 PEC [18].

\begin{tabular}{|c|c|c|c|}
\hline Photoactive material & $\mathrm{V}_{\mathrm{OC}}(\mathrm{mV})$ & $\mathrm{J}_{\mathrm{SC}}\left(\mu \mathrm{A} / \mathrm{cm}^{2}\right)$ & Reference \\
\hline P3HT: $\mathrm{C}_{60}(1: 1)$ & 97.8 & 7.28 & {$[18]$} \\
\hline P3HT:PCBM $(1: 1)$ & 140.0 & 28.4 & This work \\
\hline
\end{tabular}

Figure 3 illustrates the schematic of operation of the P3HT:PCBM based solid-state PECs. The energy levels of the LUMO and the HOMO of P3HT are at $-3.53 \mathrm{eV}$ and $-5.2 \mathrm{eV}$, respectively [32] while those of PCBM are at $-3.75 \mathrm{eV}$ and $-6.1 \mathrm{eV}$, respectively [33]. Thus, photogenerated free electrons can be transferred from the LUMO of P3HT directly to the electrolyte or to the LUMO of PCBM and then to the electrolyte where they reduce $\mathrm{I}_{3}{ }^{-}$to $\mathrm{I}^{-}, \mathrm{E}_{\text {redox }}$ $\left(\mathrm{I}_{3}{ }^{-} / \mathrm{I}^{-}\right)=-4.9 \mathrm{eV}$ [34]. $\mathrm{I}_{3}{ }^{-}$is regenerated when $\mathrm{I}^{-}$is oxidized at the counter electrode (anode). In the mean time, the photogenerated holes move to the back contact (ITO) of the PEC through the polymer network. Thus, light energy is converted to electrical energy without net chemical change.

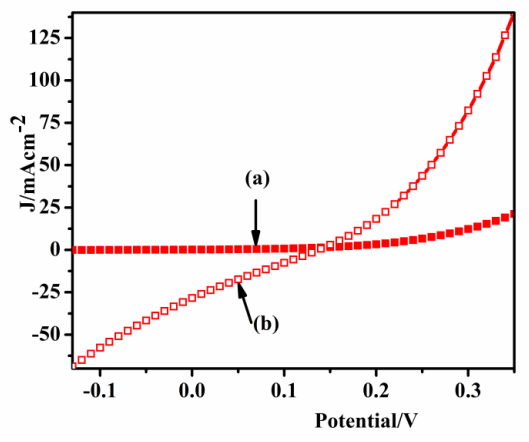

Figure 2. Current density-voltage characteristics of ITOIP3HT:PCBMIPOMOE:I ${ }_{3}^{-} / \mathrm{I}^{-} \mid \mathrm{PEDOT}{ }^{-}{ }^{-}$ cell (a) in the dark and (b) under illumination through front side with light intensity of $100 \mathrm{mWcm}^{-2}$.

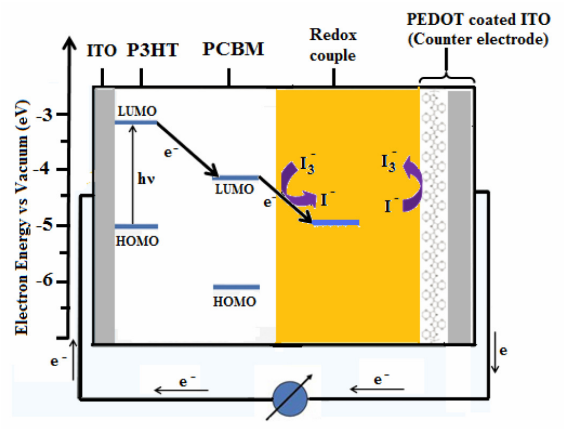

Figure 3. Schematic of operation of the P3HT:PCBM-based solid-state PEC. 
The dependence of $J_{S C}$ and $V_{O C}$ on time

The parameters that are used to describe solar cells are short-circuit current density $\left(\mathrm{J}_{\mathrm{SC}}\right)$ and open-circuit voltage $\left(\mathrm{V}_{\mathrm{OC}}\right)$. These parameters determine the efficiency and are the key parameters in experimental investigation of solar cells.

Steady state and transient measurements of $\mathrm{J}_{\mathrm{SC}}$ and $\mathrm{V}_{\mathrm{OC}}$, established during long and short period of irradiation, are used to characterize the stability of the PECs towards illumination.

Figure 4 shows photocurrent density response to continuous illumination with light intensity of $100 \mathrm{mWcm}^{-2}$ for the ITOIP3HT:PCBMIPOMOE:I ${ }_{3}^{-} / \mathrm{I}^{-}|\mathrm{PEDOT}| \mathrm{ITO}$ solid-state PEC. The inset in Figure 4 and Figure 5 show the short-circuit current density and open-circuit voltage, respectively, as a function of time for the ITOIP3HT:PCBMIPOMOE: $\mathrm{I}_{3}{ }^{-} / \mathrm{I}^{-} \mid \mathrm{PEDOTITO}$ solidstate PEC. The illumination was made from the PEDOTIITO side (front side) with a white light intensity of $100 \mathrm{mWcm}^{-2}$. The generation of photovoltage and photocurrent were characterized by a rise to a steady state value when the light is switched on and decay at approximately the same rate when the light is switched off. The stability of the photocurrent was very good. The short-circuit photocurrent density and open-circuit voltage obtained from the transient measurements were $26.28 \mu \mathrm{A} / \mathrm{cm}^{2}$ and $142.5 \mathrm{mV}$, respectively. The results of time dependence study show that the steady state $\mathrm{J}_{\mathrm{SC}}$ and $\mathrm{V}_{\mathrm{OC}}$ values are consistent with those obtained from the $\mathrm{J}-\mathrm{V}$ curve.

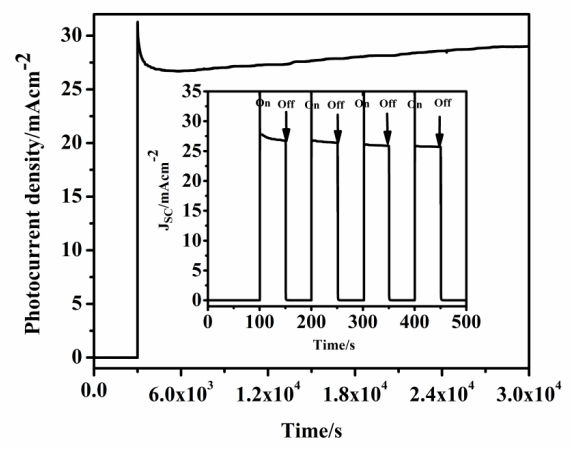

Figure 4. Photocurrent density response to continuous illumination with light intensity of 100 $\mathrm{mWcm}^{-2}$ for the ITOIP3HT:PCBM|POMOE:I ${ }_{3}{ }^{-} / \mathrm{I}^{-}|\mathrm{PEDOT}| \mathrm{ITO}$ solid-state PEC from the front side. The inset shows the photocurrent response to switching illumination on and off.

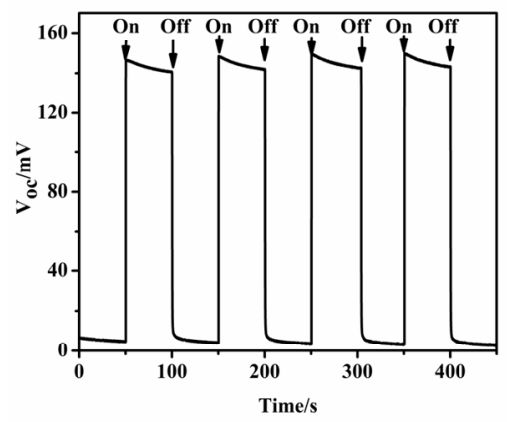

Figure 5. Photovoltage response to switching illumination on and off from the front side of ITOIP3HT:PCBM|POMOE: ${ }_{3}{ }^{-} / \mathrm{I}^{\mid} \mid \mathrm{PEDOTITO}$ solid-state PEC with light intensity of $100 \mathrm{mWcm}^{-2}$. 
Photocurrent action spectra

The photocurrent collected at a different wavelength, relative to the number of photons incident on the surface at that wavelength, determines the spectral response of the device (sometimes known as the external quantum efficiency or collection efficiency at each wavelength). Light of different wavelengths is absorbed at different depths in the conjugated polymer film. The ability of a solar cell to generate photocurrent at a given wavelength of the incident light is measured by the incident monochromatic photon to current conversion efficiency (IPCE), defined as the number of electrons generated per number of incident photons. It can be calculated using the following equation:

$$
I P C E \%=\frac{1240 J_{S C}}{\lambda I_{\text {in }}},
$$

where $\mathrm{J}_{\mathrm{SC}}$ is the short-circuit current density $\left(\mu \mathrm{Acm}^{-2}\right), \lambda$ the excitation wavelength $(\mathrm{nm})$ and $\mathrm{I}_{\mathrm{in}}$ the photon flux $\left(\mathrm{Wm}^{-2}\right)$.

The photocurrent action spectrum plotted in terms of IPCE\% versus wavelength under front-

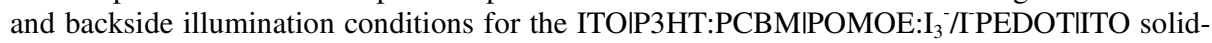
state PEC is shown in Figure 6. The wavelength was varied at $10 \mathrm{~nm}$ intervals and the photocurrent was measured at each wavelength. For each wavelength, the light intensity of the source was kept constant at $100 \mathrm{~mW} / \mathrm{cm}^{2}$ but correction for monochromatic intensity at different wavelengths was made when calculating the IPCE. The maximum value of the IPCE is found to be $1.52 \%$ for front side illumination and $0.17 \%$ for backside illumination at a wavelength of $510 \mathrm{~nm}$.

Comparison of front side and backside conversion efficiencies showed that front side illumination resulted in higher conversion efficiency than backside illumination at the maximum absorbance. The reason behind this difference lies on the optical filtering effect of the P3HT:PCBM composite film. When light is illuminated from the backside, only a small fraction of the excitons (bound electron-hole pairs) produced by light absorption reach the interface to dissociate into carriers. Moreover, the presence of a high density of the traps in the film reduces the number of carriers for the photocurrent generation. The greater the distance from the surface, the smaller is the probability for an exciton to reach the interface and dissociate into carriers.

The IPCE\% values at the maximum absorbance for pure P3HT-based PEC is $0.024 \%$ under front side and $0.003 \%$ under backside illumination conditions [17], and for $\mathrm{P} 3 \mathrm{HT}: \mathrm{C}_{60}$ composite based PEC is $0.43 \%$ under front side and $0.01 \%$ under back side [18] which is smaller than what has been reported here for the P3HT:PCBM-based PEC.

Comparison of the optical absorption spectrum and spectral photoresponse can be used to identify the active junction responsible for the photoelectrochemical phenomena. If illumination through the front side of the PEC produces a spectral response that corresponds to the absorption spectrum of the P3HT:PCBM composite film, then P3HT:PCBMlelectrolyte junction is responsible for the photoelectrochemical phenomena. If illumination from backside produces a matching spectrum, then it is the P3HT:PCBMIITO junction that is active. 


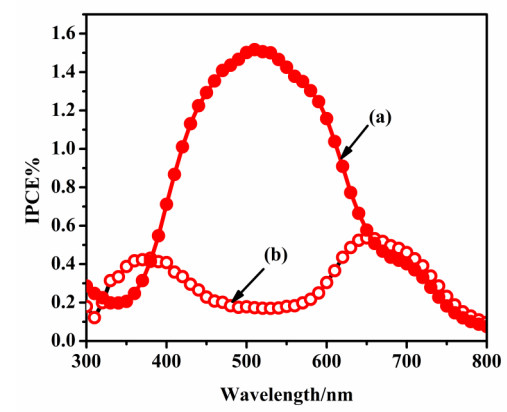

Figure 6. Photocurrent action spectra for ITOIP3HT:PCBM|POMOE:I ${ }_{3}^{-} / \mathrm{I}^{-}|\mathrm{PEDOT}| \mathrm{ITO}$ solidstate PEC illuminated through (a) front side and (b) back side.

The normalized absorption spectrum of the P3HT:PCBM composite film as compared to normalized photocurrent action spectra of ITOIP3HT:PCBMI POMOE:I ${ }_{3}^{-} / \mathrm{I}^{-} \mid \mathrm{PEDOT}$ ITTO solidstate PEC for front side and backside illumination conditions are shown in Figure 7. The wavelength dependence of the IPCE\% obtained from front side illumination closely resembles the absorption spectrum of P3HT:PCBM film, indicating that the photoactive junction is the P3HT:PCBMlelectrolyte interface. When illuminated through the backside, there is a mismatch between the action spectrum and the optical absorption spectrum. This can be explained as follows. When the absorption constant is high, excitons are created very close to the ITOlphotoactive layer (backside). Therefore, only a small fraction of the light reaches the barrier regions and as a result charge carriers are lost due to recombination or trapping, which decreases the photocurrent. However, at wavelengths where the absorption constant is low, light penetrates deeper and the excitons will be created much closer to the photoactive electrode/polymer electrolyte interface so that a relatively large photocurrent will be measured. Only charge carriers in or near the space charge region of the active junction have a significant probability of being collected by the external circuit. Thus, photons absorbed away from the active junction generally have no effect on photocurrent generation.

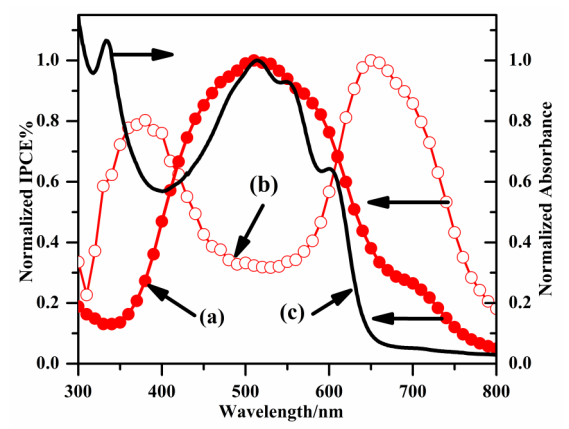

Figure 7. Normalized photocurrent action spectrum of ITOIP3HT:PCBMIPOMOE:I ${ }_{3}^{-} / \mathrm{I}^{-}$ IPEDOTIITO for illumination through (a) front side, (b) back side, and (c) normalized optical absorption spectrum of P3HT:PCBM blend deposited on glass. 
The dependence of $J_{S C}$ and $V_{O C}$ on light intensity

For organic and some inorganic solar cells, the $\mathrm{J}_{\mathrm{sc}}$ increases with increasing light intensity $\left(\mathrm{I}_{\mathrm{in}}\right)$ and is proportional to $\mathrm{I}_{\text {in }}^{\alpha}$ [35]. Thus, a plot of $\log \mathrm{J}_{\mathrm{SC}}$ versus $\log \mathrm{I}_{\text {in }}$ yields a straight line whose slope is characteristic of the photoactive material. The plot of $\log \mathrm{J}_{\mathrm{SC}}$ versus $\log \mathrm{I}_{\text {in }}$ of the ITOI P3HT:PCBM|POMOE: $\mathrm{I}_{3}{ }^{-} / \mathrm{I}^{-} \mathrm{PEDOT}$ |ITO solid-state PEC is shown in Figure 8. The illumination intensity was varied from 0.01 to $100 \mathrm{mWcm}^{-2}$. The $\mathrm{J}_{\mathrm{sc}}$ increases with illumination intensity and is proportional to $I^{\alpha}$ in, where $\alpha$ is the power factor and $I_{i n}$ is the incident light intensity. The plot of $\log \mathrm{J}_{\mathrm{SC}}$ versus $\log \mathrm{I}_{\text {in }}$ yielded a straight line with $\alpha=0.94$ which is close to 1 . Such dependence implies there is no bimolecular recombination of excitons [35-38].

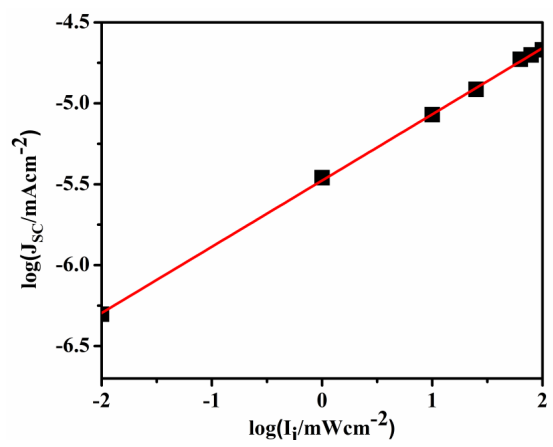

Figure 8. Plot of $\log \mathrm{J}_{\mathrm{sc}}$ versus $\log \mathrm{I}_{\text {in }}$ of ITO|P3HT:PCBM|POMOE: $\mathrm{I}_{3}{ }^{-} / \mathrm{I}^{-} \mid \mathrm{PEDOT}$ |ITO solid-state PEC.

For Schottky junction solar cells under open-circuit conditions, no net current will flow through the junction. Thus, Equation (2) can be rearranged to yield the following relationship:

$$
V_{O C}=\frac{n k T}{q} \ln \left[\left(\frac{I_{p h}}{I_{o}}\right)+1\right] \approx \frac{n k T}{q} \ln \left(\frac{I_{p h}}{I_{o}}\right), \text { for } \mathrm{I}_{\mathrm{ph}} \gg \mathrm{I}_{0}
$$

As can be seen from Equation (4), $\mathrm{V}_{\mathrm{OC}}$ increases logarithmically with the light intensity because $\mathrm{I}_{\mathrm{ph}}$ is linearly proportional to the incident light intensity. The plot of $\mathrm{V}_{\mathrm{OC}}$ versus $\log \mathrm{I}_{\text {in }}$ of the ITOIP3HT:PCBM|POMOE: $\mathrm{I}_{3}{ }^{-} / \mathrm{I}^{-}|\mathrm{PEDOT}| \mathrm{ITO}$ solid-state PEC is shown in Figure $9 . \mathrm{V}_{\mathrm{OC}}$ increases logarithmically with the light intensity, in agreement with the projected behaviour of Schottky barrier solar cells [39]. 


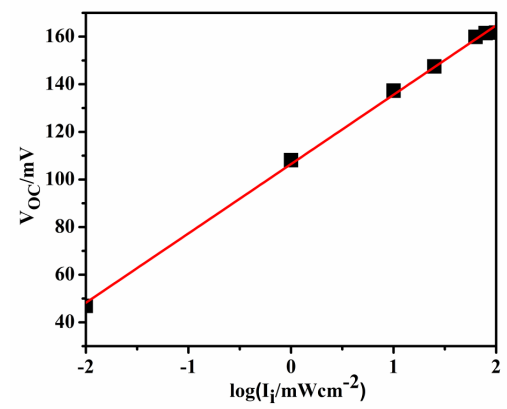

Figure 9. Plot of $\mathrm{V}_{\mathrm{OC}}$ versus $\log \mathrm{I}_{\text {in }}$ of ITOIP3HT:PCBMIPOMOE:I $\mathrm{I}_{3}^{-} / \mathrm{I}^{-}|\mathrm{PEDOT}| \mathrm{ITO}$ solid-state PEC.

\section{CONCLUSIONS}

In this study, a solid-state PEC was constructed from mixtures of P3HT and PCBM, in bulk heterojunction structure. Photoelectrochemical and optical properties of this organic device was studied together with the dependence of $\mathrm{J}_{\mathrm{SC}}$ and $\mathrm{V}_{\mathrm{OC}}$ on illumination intensity. The photoelectrochemical properties of a solid-state PEC based on blends of P3HT and PCBM were compared with the corresponding blends of P3HT and $\mathrm{C}_{60}$ PECs. An open-circuit voltage of 140 $\mathrm{mV}$ and a short-circuit current density of $28.4 \mu \mathrm{A} / \mathrm{cm}^{2}$ at light intensity of $100 \mathrm{~mW} / \mathrm{cm}^{2}$; IPCE\% of $1.52 \%$ for front side illumination and IPCE\% of $0.17 \%$ for backside illumination at a wavelength of $510 \mathrm{~nm}$ were obtained. Compared with P3HT: $\mathrm{C}_{60}$ PEC reported earlier the results show that higher $\mathrm{V}_{\mathrm{OC}}$ was measured and $\mathrm{J}_{\mathrm{SC}}$ and IPCE\% values were increased by many folds. The photocurrent action spectra studies show that the active junction responsible for the photocurrent generation is that between the P3HT:PCBM and the solid polymer electrolyte. Photocurrent response to continuous illumination also has shown that the P3HT:PCBM PEC has a greater stability for light illumination.

\section{REFERENCES}

1. Becquerel, A.E. C. R. Acad. Sci., 1839, 9, 145.

2. West, W. Proc. VogelCent. Symp. Photogr. Sci. Eng. 1974, 18, 35.

3. Gerischer, H.; Tributsch, H. Ber. Bunsenges. Phys. Chem. 1968, 72, 437.

4. Hauffe, K.; Danzmann, H.J.; Pusch, H.; Range, J.; Volz, H. J. Electrochem. Soc. 1970, 117, 993.

5. Myamlin, V.A.; Pleskov, Y.V. Electrochemistry of Semiconductors, Plenum Press: New York; 1967.

6. O'Regan, B.; Grätzel, M. Nature 1991, 353,737.

7. Ellis, A.B.; Kaiser, S.W.; Wrighton, M.S. J. Am. Chem. Soc. 1976, 98, 1635.

8. Ellis, A.B.; Bolts, J.M.; Wrighton, M.S. J. Electrochem. Soc. 1977, 124, 1603.

9. Hodes, G.; Manassen, J.; Cahen, D. Nature 1976, 261, 403.

10. Miller, B.; Heller, A. Nature 1976, 262, 680.

11. Fujishima, A.; Honda, K. Nature 1972, 238, 37.

12. Fujishima, A.; Honda, K. Bull. Chem. Soc. Jpn. 1971, 44, 1148.

13. Yohannes, T.; Solomon, T.; Inganas, O. Synth. Met. 1996, 82, 215.

14. Yohannes, T.; Inganas, O. J. Electrochem. Soc. 1996, 143, 2310. 
15. Yohannes, T.; Inganas, O. Sol. Energy Mater. Sol. Cells 1998, 51, 193.

16. Yohannes, T.; Inganas, O. Synth. Met. 1999, 107, 97.

17. Adi, M.; Yohannes, T.; Solomon, T. Sol. Energy Mater. Sol. Cells 2004, 83, 301.

18. Mengesha, U.; Yohannes, T. Sol. Energy Mater. Sol. Cells 2006, 90, 3508.

19. Padinger, F.; Brabec, C.J.; Fromherz, T.; Hummelen, J.C.; Sariciftci, N.S. Opto-Electr. 2000, 8, 280.

20. Sirringhaus, H.; Tessler, N.; Friend, R.H. Science 1998, 280, 1741.

21. Craven, J.R.; Mobbs, R.H.; Booth, C.; Giles, J.R.M. Makromol. Chem. Rapid Commun. 1986, 7,81 .

22. Craven, J.R.; Nicholas, C.V.; Webster, R.; Wilson, D.J.; Mobbs, R.H.; Morris, G.A.; Heatley, F.; Booth, C.; Giles, J.R.M. Br. Polym. J. 1987, 19, 509.

23. Nicholas, C.V.; Wilson, D.J.; Booth, C.; Giles, J.R.M. Br. Polym. J. 1988, 20, 289.

24. Linden, E.; Owen, J.R. Br. Polym. J. 1988, 20, 237.

25. Nekoomanesh, M.; Nagae, H.S.; Booth, C.; Owen, J.R. J. Electrochem. Soc. 1992, 139, 3046.

26. Skotheim, T.A.; Feldberg, S.W.; Armand, M.B. J. Phys. Paris Colloq. 1983, C 3, 615.

27. Aagae, S.; Nekoomanesh, H.M.; Booth, C.; Owen, J.R. Solid State Ionics 1992, 53-56, 1118.

28. Tan, M.X.; Laibinis, P.E.; Nguyen, S.T.; Kesselman, J.M.; Stanton, C.E.; Lewis, N.S. Principles and applications of semiconductor photochemistry in Progress in inorganic Chemistry, Karlin, K.D. (Ed.), John Wiley and Sons: California; 1994; pp. 69-82.

29. Brabec, C.J.; Cravino, A.; Meissner, D.; Sariciftci, N.S.; Fromherz, T.; Rispens, M.T.; Sanchez, L.; Hummelen, J.C. Adv. Funct. Mater. 2001, 11, 374.

30. Liu, J.; Shi, Y.; Yang, Y. Adv. Funct. Mater. 2001, 11, 420.

31. Shaheen, S.E.; Brabec, C.J.; Padinger, F.; Fromherz, T.; Hummelen, J.C.; Sariciftci, N.S. Appl. Phys. Lett. 2001, 78, 841.

32. Al-Ibrahim Al-Ibrahim, M.; Rotha, H.-K; Zhokhavetsb, U.; Gobsch, G.; Sensfuss, S. Sol. Energy Mater. \& Sol. Cells 2005, 85, 13.

33. Brabec, C.J.; Sariciftci, N.S.; Hummelen, J.C. Adv. Funct. Mater. 2001, 11, 15.

34. Hagfeldt, A.; Grätzel, M. Acc. Chem. Res. 2000, 33, 269.

35. Meier, H. Organic Semiconductors, Verlag Chemie: Berlin; 1974; pp. 318-321.

36. Glenis, S.; Tourillon, G.; Garnier, F. Thin Solid Films 1986, 139, 221.

37. Glenis, S.; Horowitz, G.; Tourillon, G.; Garnier, F. Thin Solid Films 1984, 111, 93.

38. Loutfy, R.O.; Sharp, J.H.; Hsiao, C.K.; Ho, R. J. Appl. Phys. 1981, 52, 5218.

39. Sze, S.M.; Ng., K.K. Photodetectors and Solar Cells in Physics of Semiconductor Devices, 3rd ed., John Wiley and Sons: New Jersey; 2003; pp. 719-736. 